\title{
NEUMONÍA BACTERIANA CON DESARROLLO DE ABSCESOS PULMONARES SECUNDARIOS A INFECCIÓN CAUSADA POR STREPTOCOCCUS INTERMEDIUS PROVENIENTE DE ABSCESO DENTAL
}

\author{
Álvarez Herrera, Leonardo \\ Médico General, Servicio de Medicina Laboral, Hospital Dr. Rafael Ángel Calderón Guardia, San José, Costa Rica.
}

Resumen: A continuación se presenta el caso de un paciente masculino de 29 años, con los únicos antecedentes personales patológicos de psoriasis y asma bronquial, el cual desarrolló neumonía con múltiples abscesos pulmonares bilaterales causados por la bacteria Streptococcus intermedius proveniente de un absceso dental.

El paciente requirió internamiento hospitalario por un lapso de 17 días y recibió tratamiento con Ampicilina/Sulbactam 1,5 gramos cada 6 horas intravenoso por un período de 2 semanas, mostrando franca mejoría clínica, por lo cual se egresó con el mismo tratamiento antibiótico vía oral con la indicación de tomarlo un mes más.

Palabras clave: Streptococcus intermedius, Streptococcus milleri, abscesos pulmonares, neumonía bacteriana

Abstract: A case of a 29 years old male patient is presented; having asthma and psoriasis as his only personal pathological antecedents he developed pneumonia with multiple pulmonary bilateral abscesses caused by the bacteria Streptococcus intermedius coming from a dental abscess.

The patient required hospital admission for 17 days and received endovenous treatment with Ampilicin/Sulbactam in a dose of $1,5 \mathrm{~g}$ each 6 hours for 2 weeks, showing clinical recovery and being discharged of the health center with the same antibiotic treatment for one more month administered via oral.

Key words: Streptococcus intermedius, Streptococcus milleri, pulmonary abscesses, bacterial pneumonia 


\section{CASO CLÍNICO}

Masculino de 29 años portador de asma bronquial y psoriasis. Inicia el 5 de abril del 2010 con dolor punzante a nivel dorsal izquierdo sin ningún otro síntoma asociado. Se manejó inicialmente como contractura muscular vs. osteocondritis. A pesar de tratamiento con AINES persiste con dolor y se documenta fiebre de $38^{\circ} \mathrm{C}$. Se realiza radiografía de tórax la cual no evidencia cambios importantes. Se realizan exámenes de laboratorio en los cuales se destaca lo siguiente:

Tabla \#1. Exámenes de laboratorio

\begin{tabular}{|c|c|c|}
\hline \multicolumn{3}{|c|}{ Hemograma } \\
\hline Parámetro & Resultado & Valor de referencia \\
\hline Leucocitos & $11.400 \mathrm{uds} / \mu \mathrm{l}$ & $5.000-10.000 \mathrm{uds} / \mu \mathrm{l}$ \\
\hline Segmentados & $67 \%$ & $40-70 \%$ \\
\hline Bandas & $1 \%$ & $0-4 \%$ \\
\hline Linfocitos & $26 \%$ & $20-45 \%$ \\
\hline V.E.S & $70 \mathrm{~mm} / \mathrm{h}$ & $0-15 \mathrm{~mm} / \mathrm{h}$ \\
\hline P.C.R & $0,3 \mathrm{mg} / \mathrm{dl}$ & $0-0,5 \mathrm{mg} / \mathrm{dl}$ \\
\hline \multicolumn{3}{|c|}{ Química sanguínea } \\
\hline Parámetro & Resultado & Valor de referencia \\
\hline ALT & $39,0 \mathrm{U} / \mathrm{L}$ & hasta $50 \mathrm{U} / \mathrm{L}$ \\
\hline AST & $23,1 \mathrm{U} / \mathrm{L}$ & hasta $50 \mathrm{U} / \mathrm{L}$ \\
\hline \multicolumn{3}{|c|}{ Inmunología } \\
\hline Parámetro & Resultado & Valor de referencia \\
\hline $\begin{array}{l}\text { Serología por } \\
\text { Epstein Barr } \\
\text { Virus, IgM }\end{array}$ & $36 U$ & Positivo $>11 \mathrm{U}$ \\
\hline $\begin{array}{l}\text { Serología por } \\
{ }^{*} \mathrm{CMV} \text {, IgM }\end{array}$ & S/CO 0,5 & $\mathrm{S} / \mathrm{CO}<0,6$ negativo \\
\hline *H.S.V IgM & negativo & negativo \\
\hline
\end{tabular}

El paciente inicia tratamiento antiviral debido a sospecha de infección por Epstein Barr, sin embargo persiste con dolor punzante tipo pleurítico a nivel dorsal izquierdo y fiebre de $38.5^{\circ} \mathrm{C}-3^{\circ} \mathrm{O}$ C. A los 10 días de iniciados los síntomas comienza a presentar tos productiva con expectoración amarillenta.

Consulta a nivel particular con médica infectóloga el 16 de abril y en el examen físico se describe a un paciente con criterios de sepsis encontrándose febril $\left(39^{\circ} \mathrm{C}\right)$, taquicárdico, normotenso, con ataque al estado general, con pérdida de peso de 6 $\mathrm{kg}$ en un lapso aproximado de 10 días, eupneico y con dolor franco tipo pleurítico ahora bilateral. Como hallazgo importante se evidencia absceso dental en pieza superior con una evolución de aproximadamente 22 días según manifestó el paciente, el cual drenó espontáneamente y no recibió tratamiento antibiótico.

Ante los hallazgos descritos se decide referir al Servicio de Emergencias del Hospital Dr. Rafael Ángel Calderón Guardia para descartar la posibilidad diagnóstica de endocarditis bacteriana. Ahí es valorado $\mathrm{y}$ se decide ingresar para completar estudios y tratamiento.

Se toma muestra de hemocultivo de ingreso que posteriormente sería reportado negativo por bacterias. Se le realiza radiografías de tórax en las cuales se evidencia la presencia de imágenes sugestivas de masas pulmonares bilaterales sin documentarse la existencia de infiltrados ni derrame pleural, por lo cual se decide realizar tomografía axial computarizada (T.A.C) de tórax con medio de contraste en el cual se describe lo siguiente:

"Como hallazgo principal se observa múltiples lesiones nodulares aproximadamente 4 en pulmón izquierdo $y \quad 1$ en derecho, la mayor mide aproximadamente $4 \mathrm{~cm}$. y presenta un halo en vidrio deslustrado alrededor lo que sugiere un origen inflamatorio infeccioso. Con el medio de contraste realza periféricamente con mayor atenuación hacia el centro. Las lesiones contactan con la pleura en la mayoría de los casos. Hay escaso derrame pleural derecho. En este momento no hay cavitación de las lesiones. Mediastino sin masas ni adenopatías. En base a la clínica y hallazgos radiológicos se sugiere un proceso infeccioso por un germen atípico. Dentro de las probabilidades diagnósticas se debe considerar: abscesos iniciales por embolismo séptico; no se puede descartar aspergilosis angioinvasiva (paciente es asmático); tuberculosis, bacterias atípicas como Chlamydia". 


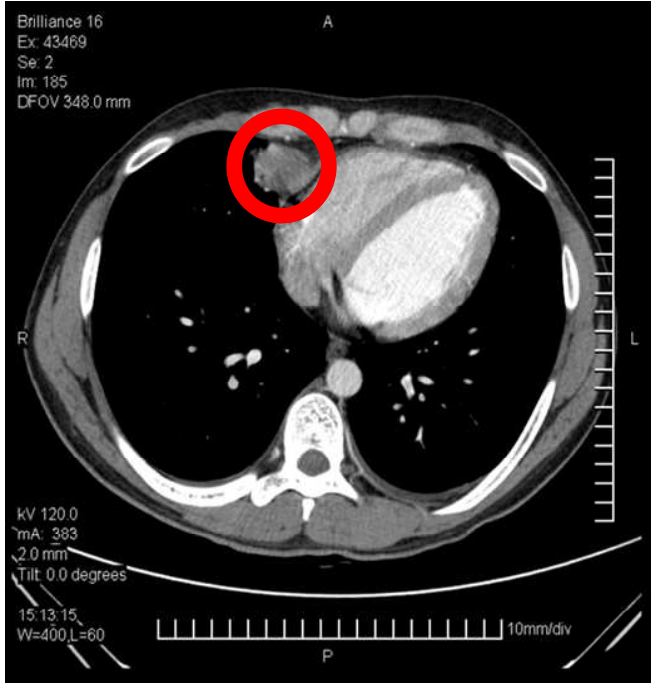

Figura $\mathrm{N}^{\circ} 1$

Absceso pulmonar izquierdo

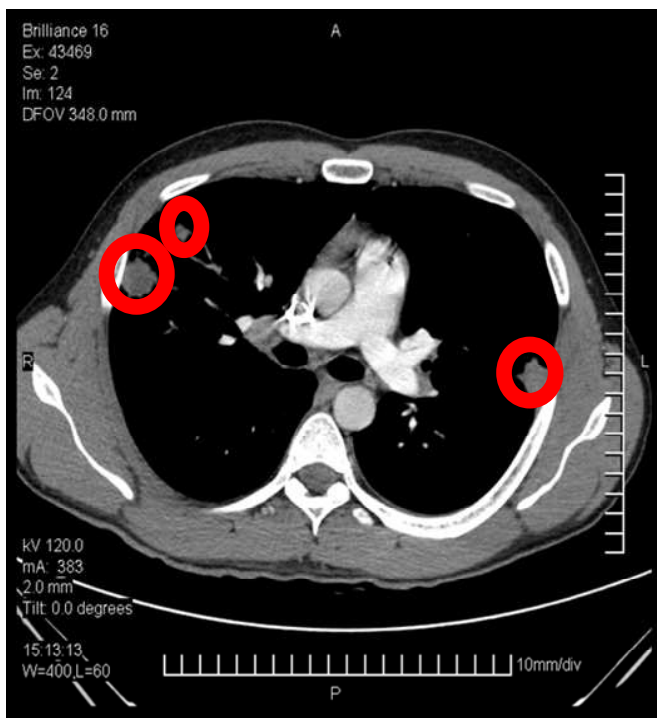

Figura $\mathrm{N}^{\circ} 2$

Abscesos pulmonares bilaterales

Se le realiza ecocardiograma transtorácico el cual se reporta como normal al ingreso, sin datos de valvulopatías. Se le realiza ultrasonido de abdomen el cual se reporta sin alteraciones.

Es valorado por médica infectóloga en el Servicio de Emergencias quien sugiere no iniciar tratamiento al manejarse varias posibles etiologías y en vista de que la condición clínica del paciente lo permitía. Se decide internar en el Servicio de Infectología.

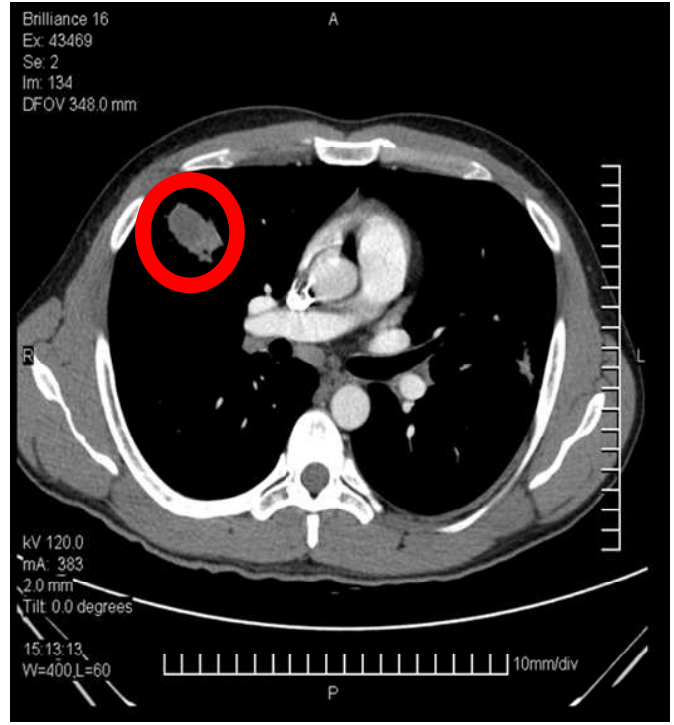

Figura $\mathrm{N}^{\circ} 3$

Absceso pulmonar izquierdo

Se recoge muestras de esputos reportándose posteriormente negativos por bacilos alcohol-ácido resistentes. El 17 de abril se decide trasladar a la Unidad de Cuidados Intensivos para continuar estudios y realizar monitoreo hemodinámico. La condición clínica del paciente es similar. Se vuelve a tomar muestra para hemocultivo que posteriormente también fue reportado como negativo.

El 18 de abril se realiza ecocardiograma transesofágico en el cual no se encontró evidencia de trombos, masas ni vegetaciones valvulares y se reportó una anatomía y función cardíaca normal. A pesar de que no hay deterioro clínico del paciente, el recuento leucocitario aumenta a 16. $250 \mathrm{uds} / \mu \mathrm{l}$, los reactantes de fase aguda siguen en aumento.

Se decide realizar punción pulmonar transtorácica guiada por T.A.C lográndose obtener material purulento; no se presentan complicaciones derivadas del procedimiento. Se realiza el mismo día broncoscopia con lavado bronquial. Dentro de los hallazgos de importancia se anota: "... árbol bronquial derecho con importante proceso inflamatorio, secreciones purulentas que provienen del lóbulo medio e inferior". "No se evidencian lesiones endobronquiales ni compresiones extrínsecas". "Árbol bronquial izquierdo con proceso inflamatorio moderado, con secreciones purulentas sin lesiones endobronquiales ni compresiones". 
Sin tener aún el posible agente causal pero, ante los hallazgos de la punción pulmonar y la broncoscopia y sospechando un agente piógeno como posible causal, se maneja como diagnóstico más probable neumonía con abscesos pulmonares múltiples secundarios a émbolos sépticos debido al absceso de origen dental y se decide iniciar terapia antibiótica con Ampicilina/Sulbactam 1,5 g c/6 horas I.V.

El análisis microbiológico de lavado bronquial reportó lo siguiente: "Tinción de Ziehl-Neelsen negativo por bacilos alcohol ácido resistentes". "Tinción de Gram: se observan escasos cocos Gram positivos". "Tinción de Wright: no se observan otros microorganismos". "Cultivo por hongos: negativo a los tres días". "Cultivo por bacterias: negativo".

El análisis microbiológico del material obtenido a través de la punción pulmonar reporta la presencia de la bacteria Streptococcus intermedius, siendo negativo por otras bacterias y hongos. La muestra fue analizada tanto por el Laboratorio Clínico del Hospital Dr. Rafael Ángel Calderón Guardia como por el Laboratorio de Enfermedades Infecciosas de la Cátedra de Patología de la Universidad de Costa Rica, obteniendo el mismo resultado y por ende estableciendo a esta bacteria como agente causal del proceso infeccioso.

El paciente evoluciona de manera satisfactoria normalizando el recuento leucocitario y mostrándose afebril a partir del día 22 de abril del 2010. Se le realiza T.A.C de tórax de control en el cual se evidencia disminución importante de las lesiones. El paciente cumple 2 semanas completas de tratamiento intravenoso y se decide egresar y completar 1 mes más de tratamiento vía oral.

\section{DISCUSIÓN}

\section{Streptococcus intermedius}

La bacteria Streptococcus intermedius (S. intermedius) pertenece al grupo denominado como Streptococcus milleri (S. milleri) en el cual se encuentran también el S. anginosus y el S. constelatus [1]. En 1965 0. Guthof fue el primero en utilizar el nombre de $S$. milleri refiriéndose a especies de estreptococos no hemolíticos encontrados en la cavidad oral [1]. Se ha encontrado este grupo bacteriano también en la flora fecal y vaginal normal así como en el apéndice cecal [1]. Aunque son organismos comensales, la desregulación de la flora bacteriana de la mucosa del huésped puede dar pie a la infiltración de estas bacterias en los tejidos subyacentes y originar procesos infecciosos [2].

La característica clínica más importante del grupo S. milleri es su tendencia a causar infecciones supurativas en todo el cuerpo que van desde abscesos dentales hasta infecciones severas en diferentes órganos tales como neumonías, abscesos hepáticos y cerebrales [1,3,4]. Algunos estudios que han detallado el sitio donde se ha aislado alguna de estas bacterias, sugieren que el S. anginosus se aisla con más frecuencia en muestras de sangre, tracto gastrointestinal $\mathrm{y}$ urogenital, mientras el S. intermedius tiende a producir infecciones a nivel de cabeza, cuello y tracto respiratorio [5]. Otros estudios han evidenciado que el S. intermedius es un agente potencialmente causal, aunque poco común, de endocarditis infecciosa [6].

Se ha sugerido también que la bacteremia causada por alguna de las bacterias pertenecientes al grupo S. milleri es un indicador significativo de abscesos ocultos [3].

Algunos factores predisponentes para desarrollar empiema o abscesos pulmonares producto de la infección por S. milleri son: alteraciones de la mucosa respiratoria tales como sinusitis, enfermedad periodontal, otras como perforación esofágica, cirugía torácica, neumonía previa, malignidad, enfermedad neurológica, abuso de alcohol y diabetes [7].

Relación entre patología oral y enfermedad fuera de la cavidad oral.

Se han propuesto 3 mecanismos mediante los cuales se establecen vías de relación probable entre infección en cavidad oral y efectos secundarios a nivel sistémico [8].

1- Infección a distancia: las infecciones orales y los procedimientos dentales pueden causar bacteremias transitorias. Normalmente estas bacterias son eliminadas por el sistema retículo endotelial del cuerpo, sin embargo, si encuentran condiciones favorables en un sitio específico podrían multiplicarse y causar una infección a distancia [8].

2- Lesión a distancia: Algunas bacterias Gram positivas y Gram negativas tienen la capacidad de producir proteínas difusibles (exotoxinas) con efecto nocivo. Por otra parte existen lipopolisacáridos que forman parte de las membranas celulares bacterianas que al producirse la muerte celular son liberadas al torrente sanguíneo causando una gran cantidad de 
manifestaciones patológicas en el huésped (endotoxinas) [8].

3- Inflamación a distancia: Antígenos solubles podrían ingresar al torrente sanguíneo y reaccionar con anticuerpos específicos circulantes formando complejos macromoleculares. Estos inmunocomplejos pueden causar un sinnúmero de reacciones inflamatorias agudas o crónicas en los sitios en los cuales se depositen [8].

\section{Neumonía bacteriana}

Los patógenos microbianos pueden infectar las vías respiratorias inferiores de varias formas: aspiración de los microorganismos que colonizan la orofaringe, inhalación de aerosoles infecciosos, por diseminación hematógena a partir de un foco infeccioso extrapulmonar, inoculación directa y diseminación por contigüidad con otro sitio infectado [9].

Las personas normales portan transitoriamente en la nasofaringe, varias veces al año, patógenos pulmonares comunes, tales como Streptococcus pneumoniae, Streptococcus pyogenes, Mycoplasma pneumoniae, Haemophilus influenzae y Moraxella catarrhalis. Los surcos gingivales y la placa dental del ser humano son fuentes de patógenos pulmonares anaerobios tales como Porphyromonas gingivalis, Prevotella melaninogenica, Fusobacterium nucleatum, especies de actinomyces, espiroquetas y estreptococos anaerobios, lográndose aislar de esos sitios más de 1011 unidades formadoras de colonias (CFU) de microorganismos por gramo [9].

Los agentes causales de neumonía bacteriana usualmente varían en relación a circunstancias como la vida del paciente, su ocupación, los antecedentes de viajes, la exposición a animales o mascotas, las enfermedades en los contactos del paciente y la curva epidemiológica de brotes en la comunidad. La frecuencia relativa de diversos patógenos pulmonares varía según el contexto en que se adquirió la infección, ya sea la comunidad, residencia de ancianos u hospital [9].

Las bacterias más comúnmente relacionadas con neumonía adquirida en la comunidad son Streptococcus pneumoniae, Haemophillus influenzae, Chlamydia pneumoniae. Se calcula que los bacilos entéricos Gram negativos y Pseudomonas aeruginosa, causas poco frecuentes de neumonía adquirida en la comunidad, son responsables de más del $50 \%$ de las neumonías hospitalarias, siendo Staphylococcus aureus responsable de más del 10\% [9]. En cuanto a las neumonías adquiridas en las residencias de ancianos, la frecuencia relativa de los patógenos involucrados se sitúa entre las adquiridas en la comunidad y las hospitalarias siendo los bacilos entéricos Gram negativos y la Pseudomonas aeruginosa los más comunes [9].

El S. intermedius no es de los agentes causales más frecuentes de neumonía, por lo cual es importante la sospecha clínica y considerar la posibilidad de que se encuentre presente en el caso de un paciente con un cuadro neumónico con abscesos pulmonares o a otro nivel. De hecho, la enfermedad periodontal pareciera ser un importante factor predisponente que podría pasar inadvertido, por lo cual se recomienda realizar una revisión exhaustiva de los dientes y la boca en pacientes con presencia de neumonía [7].

\section{DIAGNÓSTICO}

Clásicamente la neumonía adquirida en la comunidad del adulto se define como un cuadro de evolución aguda, caracterizado por compromiso del estado general, fiebre, escalofríos, tos, expectoración purulenta y dificultad respiratoria de magnitud variable; asociando en el examen físico taquicardia (> 100 latidos/min), taquipnea ( $>20$ respiraciones/min), fiebre (> 37, $\left.8^{\circ} \mathrm{C}\right)$, y signos focales en el examen pulmonar: matidez, disminución del murmullo pulmonar, crepitaciones, broncofonía y egofonía [10].

La radiografía de tórax es más sensible que la exploración física para detectar la presencia de infiltrados pulmonares [9]. La mayor parte de los patógenos pulmonares produce lesiones focales; una lesión multicéntrica sugiere una infección hematógena, en cuyo caso debe investigarse la existencia de infecciones remotas tales como endocarditis o tromboflebitis [9]. La neumonía hematógena consecuencia de la embolización séptica en los pacientes con tromboflebitis o endocarditis derecha, o de bacteremia en los pacientes con endocarditis izquierda, aparece en la radiografía de tórax como múltiples zonas de infiltración pulmonar que posteriormente pueden cavitarse [9]. Por esta razón es que en el caso del paciente fue necesario descartar este tipo de complicaciones a través de estudios como ecocardiograma transesofágico y hemocultivos.

Los exámenes de laboratorio tanto hematológicos como bioquímicos no son de utilidad para precisar la etiología de la neumonía adquirida en la comunidad. Sin embargo, pueden ser importantes para establecer el pronóstico de la neumonía y ayudar a decidir la hospitalización y el tipo de tratamiento [11]. En el caso descrito se encontraron datos sugestivos de 
un cuadro infeccioso de posible etiología bacteriana, aunque no se podía descartar a priori infecciones micóticas o malignidad.

El examen de esputo continúa siendo la piedra angular en la evolución del paciente con neumonía bacteriana aguda [9]. Sin embargo, el material expectorado a menudo está contaminado por bacterias potencialmente patógenas que colonizan las vías respiratorias superiores y en ocasiones, las inferiores, sin provocar enfermedades en realidad, lo cual reduce la especificidad diagnóstica de cualquier muestra de las vías respiratorias inferiores [9]. En este caso las pruebas de esputo no brindaron información relevante para esclarecer la etiología del cuadro infeccioso.

La broncoscopia es el procedimiento invasor de referencia para la obtención de secreciones respiratorias bajas en los pacientes graves o inmunodeprimidos con neumonía compleja o progresiva; ya que permite la visión directa de las vías respiratorias bajas [9]. La toma de muestras se realiza mediante un cepillo protegido de doble cubierta (CDC), lavado broncoalveolar (LBA) o biopsia transbronquial (BTB) en el lugar de la condensación pulmonar [9].

La aspiración percutánea con aguja a nivel pulmonar es un método que se ha utilizado en ocasiones para identificar el agente causal de neumonías y abscesos pulmonares [12]. Se utiliza una aguja fina que se introduce hasta el interior de la zona de condensación pulmonar guiada por T.A.C. El procedimiento requiere la cooperación del paciente, una buena hemostasia y capacidad para manejar complicaciones como la hemorragia pulmonar o el neumotórax, que a veces se asocian con su realización [9]. En este caso el examen aportó información importante desde el punto de vista clínico al confirmar que las masas pulmonares evidenciadas en la tomografía del paciente eran causadas por un agente piógeno (se obtuvo material purulento en la aspiración) y a la vez permitió a través del cultivo del aspirado identificar el agente causal.

En un estudio de series de casos realizado en el Hospital de Valme en Sevilla España, se determinó que la complicación más frecuente de este procedimiento diagnóstico fue el neumotórax en un $14 \%$ de los pacientes a los cuales se le practicó, sin embargo a diferencia de la metodología utilizada en el caso descrito, se utilizó fluoroscopía a través de un arco en C para localizar las lesiones y determinar el sito de punción en el 100\% de los pacientes [13].

\section{TRATAMIENTO}

A los pacientes con neumonía adquirida en la comunidad y que requieren ser hospitalizados, se les debe realizar una radiografía de tórax para el establecer el diagnóstico y un estudio microbiológico precoz [9]. A la vez, el tratamiento antimicrobiano debe iniciarse por vía parenteral lo más pronto posible [9]. La falta de producción de esputo, una presentación clínica "atípica", la presencia de infiltrados radiográficos difusos en un paciente con deterioro progresivo rápido y la mala respuesta al tratamiento empírico previo, son algunas de las razones para el empleo de procedimientos invasores dirigidos a detectar el patógeno pulmonar [9].

Aunque es preciso iniciar un tratamiento antibacteriano de amplio espectro al mismo tiempo que se lleva a cabo una evaluación completa en los pacientes graves con procesos de evolución rápida, estas pautas empíricas no pueden cubrir todos los posibles patógenos sin producir una toxicidad y unos gastos innecesarios [9].

La penicilina o la ampicilina continúan siendo los fármacos más adecuados para la infección por neumococos sensibles a la penicilina [9]. Según algunos estudios la bencilpenicilina en dosis altas vía intravenosa (de 10 a 20 millones de unidades al día) , la ampicilina ( 2 g cada 6 horas), la ceftriaxona (1 o 2 gramos cada 24 horas) o la cefotaxima (1 a 2 gramos cada 6 horas) representan un tratamiento adecuado en la neumonía por cepas con resistencia intermedia a penicilina (CIM de 0.1 a $1.0 \mu \mathrm{g} / \mathrm{ml}$ ) [9].

Si no se dispone del resultado de la tinción de Gram del esputo o ésta no es interpretable, la Sociedad Americana de Enfermedades Infecciosas (I.D.S.A por sus siglas en inglés), recomienda iniciar el tratamiento empírico en los pacientes hospitalizados en una unidad médica general con un $\beta$-lactámico (p.ej. ceftriaxona o cefotaxima) o una combinación de ?lactámico/inhibidor de $\beta$-lactamasa, con $0 \quad \sin$ macrólido asociado, o con una fluoroquinolona de nueva generación sola [9].

Un estudio realizado con 44 muestras en las cuales se aisló alguna bacteria perteneciente al grupo S. milleri y que se determinó que fue el agente causal infeccioso de los pacientes estudiados entre los años 1985 y 2000, analizó la CIM (concentración inhibitoria mínima) y la concentración bactericida mínima de penicilina, ampicilina, ceftriaxona y clindamicina para S. intermedius, S. constellatus y S. anginosus. Ninguno de los organismos fue resistente a antibióticos $\beta$ lactámicos aunque algunas de las muestras 
evidenciaron una resistencia intermedia. Seis de las muestras fueron resistentes a la clindamicina con representación de cada una de las tres especies. No se encontró resistencia del S. intermedius a la ceftriaxona [14].

En un estudio que comprendió la revisión de la base de datos del Laboratorio de Microbiología de la Red de Salud de la Pontificia Universidad Católica de Chile desde agosto de 1999 a febrero del 2004,en el cual se estableció la caracterización clínica y microbiológica de las infecciones causadas por las bacterias del grupo S. milleri y su susceptibilidad a antimicrobianos, se observó que $98 \%$ de los estreptococos del grupo milleri fueron susceptibles a penicilina (99/101) y cefotaxima (99/101), en cambio se encontraron 6,9\% de cepas resistentes a eritromicina (7/101) y 5\% de las cepas fueron resistentes a clindamicina (5/101). No hubo en la serie cepas resistentes a penicilina, sólo 2 con resistencia intermedia [15].

\section{CONCLUSIONES}

En el caso presentado, la teoría más probable es que el absceso dental fuera el foco primario de infección y a partir de ahí, y por alguna de las vías de contaminación ya descritas, se produjera la neumonía por S. intermedius con el subsecuente desarrollo de abscesos pulmonares bilaterales. La condición clínica que presentó el paciente permitió realizar estudios previos a la instauración del tratamiento indicado que, si bien es cierto, no determinaron el agente causal antes del inicio de la antibióticoterapia, permitieron orientar a los médicos tratantes en lo concerniente a la etiología del cuadro. El uso de ampicilina/sulbactam ( $\beta$ lactámico/inhibidor de $\beta$-lactamasa), una de las opciones sugeridas por la I.D.S.A para tratamiento empírico en caso de pacientes hospitalizados portadores de neumonía sin germen aislado, fue efectivo para el control de la misma, demostrando mejoría clínica en el paciente y evidenciando disminución radiológica importante de las lesiones pulmonares.
2. Han J., Kerschner J. Streptococcus milleri, An Organism for Head and Neck Infections and Abscess. Arch. Otolaryngol. Head Neck Surg. 2001; 127: 650 - 654 .

3. Bert F., Bariou-Lancelin M., LambertZechovsky N. Clinical Significance of Bacteremia Involving the "Streptococcus milleri" Group: 51 Cases and Review. Clinical Infectious Diseases 1998; 27: 385-7.

4. Miedouge M, Hacini J., Grimont F., Watine J. Streptococcus intermedius: A Cause of Lobar Pneumonia with Meningitis and Brain Abscesses. Clinical Infectious Diseases 2000; 30: 396-7.

5. Caro G., RiedelI.,García P. Caracterización clínica y microbiológica de las infecciones causadas por Streptococcus grupo anginosus. Rev. Chil. Infect. 2004; 21 (3): 254-260.

6. Tran M., Caldwell-McMillan M., Khalife W. and Young V. Streptococcus intermedius causing infective endocarditis and abscesses: a report of three cases and review of the literature. BMC Infectious Diseases 2008, 8: 154.

7. Wong C., Donald F., Macfarlane J. Streptococcus milieri pulmonary disease: a review and clinical description of 25 patients. Thorax 1995; 50: 1093-1096.

8. Li X., Kolltveit K., Tronstad L., Olsen I. Systemic Diseases Caused by Oral Infection. Clin.Microbiol. Rev. 2000, 13(4): 547. DOI: 10.1128/CMR. 13.4. 547-558. 2000.

9. Harrison et al. "Principios de Medicina Interna”. Editorial Mc Graw Hill. 15a Edición, 2002. p. 1730-1734.

10. Gil R., Fernández P., Sabbagh E. Diagnóstico clínico-radiológico de la neumonía del adulto adquirida en la comunidad. Rev. Chil. Enf. Respir. 2005; 21: 89-94.

11. Jiménez P., Calvo M. Diagnóstico microbiológico de la neumonía del adulto

\section{REFERENCIAS}

1. Porta G., M. Rodríguez-Carballeira, L. Gómez, M. Salavert, N. Freixas, M. Xercavins et al. Thoracic infection caused by Streptococcus milleri. Eur. Respir. J 1998; 12: 357-362. 
adquirida en la comunidad. Rev. Chil. Infect. 2005; 22 (Supl 1): S32-S38.

12. Shinzato T., Saito A. The Streptococcus milleri Group as a Cause of Pulmonary Infections.Clinical Infectious Diseases 1995; 21(Suppl 3): S238-43.

13. Peña N., Muñoz F., Vargas J., Umbria S., Alfageme I., Umbria S., Flores C. Yield of Percutaneous Needle Lung Aspiration in Lung Abscess. Chest. 1990 Jan; 97(1): 1-2.

14. Tracy M et al. Antibiotic Susceptibilities of Genetically Characterized Streptococcus milleri Group Strains. Antimicrobial Agents and Chemotherapy, May 2001, p. 15111514.

15. Clarridge J., Attorri S., Musher D., Hebert J., Dunbar S. Streptococcus intermedius, Streptococcus constellatus, and Streptococcus anginosus ("Streptococcus milleri Group") Are of Different Clinical Importance and Are Not Equally Associated with Abscess. Clinical Infectious Diseases 2001; 32: 1511-5.

\section{INFORMACION DE AUTOR:}

Álvarez Herrera, Leonardo.

E-mail: leoalv@yahoo.com ó leoalv23@hotmail.com 